\title{
HYDROGEN PEROXIDE BLEACHING OF HARDWOOD KRAFT PULP WITH ADSORBED BIRCH XYLAN AND ITS EFFECT ON PAPER PROPERTIES
}

\author{
Lizi Li, Sanghoon Lee, Hak Lae Lee, and Hye Jung Youn \\ The adsorption of xylan on pulp fibers improves the strength properties \\ of paper. However, the optical properties are decreased significantly. \\ The objective of our research was to bleach hardwood kraft pulp with \\ adsorbed birch xylan by hydrogen peroxide and study the effect of \\ bleaching parameters on paper properties. The bleaching parameters \\ studied included bleaching temperature, time, initial $\mathrm{pH}$ as well as \\ $\mathrm{MgSO}_{4}$ dosage. The optical properties (whiteness, brightness, opacity) \\ and physical properties (tensile index, tearing index, bulk) of handsheets \\ made from the pulp bleached with different process variables were \\ measured. The results showed that better optical properties were \\ obtained with higher bleaching temperature, longer bleaching time, and \\ more $\mathrm{MgSO}_{4}$ dosage. Bleaching from an initial $\mathrm{pH}$ of 11 provided the \\ highest brightness value. On the other hand, strength properties were \\ improved with decreasing of the bleaching temperature, and increasing \\ the initial $\mathrm{pH}$ and $\mathrm{MgSO}_{4}$ dosage. The relationship between strength \\ properties and bleaching time varied depending on bleaching \\ temperature. According to the results, both good mechanical properties \\ and optical properties could be achieved when the operating parameters \\ were controlled properly. Therefore hydrogen peroxide bleaching was \\ proved to be a suitable method for bleaching hardwood kraft pulp with \\ adsorption of birch xylan.
}

Keywords: Hydrogen peroxide; Bleaching; Hardwood; Kraft pulp; Birch xylan

Contact information: Program in Environmental Materials Science, Department of Forest Science, College of Agriculture and Life Sciences, Seoul National University, Seoul 151-921, Korea ; *Corresponding author:lilizi1986@gmail.com

\section{INTRODUCTION}

Xylans are the most abundant hemicelluloses found in the cell walls of land plants, of which they can constitute more than $30 \%$ of the dry weight (Joseleau et al. 1992). Softwoods contain arabino-4-O-methylglucuronoxylan, which is substituted by one 4-O-methyl-D-glucuronic acid group per 5 or $6 \mathrm{D}$-xylose units on average. Softwood xylan also contains one $\alpha$-L-arabinose unit per 5 to 12 xylose units. In hardwoods the xylan is O-acetyl-4-O-methylglucuronoxylan. On average, every tenth xylose unit is substituted by a 4-O-methylglucuronic acid residue, and the amount of acetyl groups is 3.5-7 per ten xylose units (Schimizu 1991).

In the current trend for a more effective utilization of biomass, more and more attention has been paid to the exploitation of xylans as strength-enhancing additives for paper (Schönberg et al. 2001; Danielsson and Lindström 2005; Lindström et al. 2005; 
Köhnke et al. 2009). Adsorption of pre-isolated xylan modifies the surface morphology and surface chemistry of cellulose fibers (Westbye et al. 2006), which has a positive effect on improving strength properties of paper (Schönberg et al. 2001). Besides, adsorbed xylan is spontaneously beneficial to other paper/pulp properties, such as beatability, wettability, and resistance to hornification (Köhnke and Gatenholm 2007). Efforts have been made for the exploitation of birch, barley husk, and other agricultural waste materials as xylan extraction resources, which facilitates using pre-isolated xylan commercially at a large scale for papermaking industry applications (Westbye et al. 2008; Köhnke et al. 2009). On the other hand, the increasing amount of xylan adsorbed on fiber surface reduces the brightness of paper remarkably due to the lignin residues in extracted xylan (Lee et al. 2010). Generally, there are strong chemical and physical interactions between hemicelluloses and lignin in wood, and the so-called lignin carbohydrate complexes (LCC) are well known (Björkman 1957; Lundquist et al. 1979; Eriksson et al. 1980; Meshitsuka et al. 1982; Lawoko et al. 2005). The remaining lignin in the extracted xylan fractions has a much closer linkage with xylan (Westbye et al. 2008). Consequently, an applicable bleaching process is needed to achieve both enhanced strength and high brightness after the adsorption of xylan on pulp fibers.

Increasing concern about the environmental impact of bleaching processes with chlorine and chlorine-based compounds have provided motivation for use of elemental chlorine free (ECF) and totally chlorine free (TCF) bleaching sequences (Shatalov and Pereira 2005; Abrantes et al. 2007). These bleaching processes are based on oxygenderived compounds, among which, hydrogen peroxide has proved to be a highly efficient and competitive bleaching chemical in terms of delignification efficiency, low costs, and reducing ecological impact (Walsh 1991; Abrantes et al. 2007). As a result, it has gained increasing importance in industrial applications (Zeronian and Inglesby 1995). Peroxide primarily works under alkaline conditions when the perhydroxyl ion, $\mathrm{OOH}^{-}$, is formed as in the following reactions (Zeronian and Inglesby 1995; Johnson et al. 2002).

$$
\begin{gathered}
\mathrm{H}_{2} \mathrm{O}_{2}+\mathrm{OH}^{-} \longleftrightarrow \mathrm{OOH}^{-}+\mathrm{H}_{2} \mathrm{O} \\
\mathrm{OOH}^{-}+\text {chromophore } \longrightarrow \text { bleaching (chromophore destroyed) }
\end{gathered}
$$

Some transition metal ions such as iron, manganese, and copper accelerate the catalytic decomposition of the active perhydroxyl ion. On the other hand, other ions (e.g. $\mathrm{Mg}^{2+}, \mathrm{Ca}^{2+}$ and $\mathrm{SiO}_{3}{ }^{2-}$ ) inhibit this acceleration. Therefore, a chelation step influencing the pulp metal profile prior to bleaching is necessary. This step reduces the concentration of the transition metal within the pulp, without removing the alkaline earth metals that stabilize peroxide. Of the hundred chelating agents known, DTPA (diethylenetriamine pentaacetic acid), with eight bonding sites, is a common chelant used in the pulp and paper industry due to its ability to chelate most metal ions in a 1 to 1 ratio. (Lapierre et al. 1995; Potůček and Milichovský 2000).

Alkaline hydrogen peroxide bleaching can change the chemical, physical, and optical properties of pulp significantly; therefore adjusting the conditions of bleaching properly appears fairly essential to meet specific requirements of different paper grades (Johnson et al. 2002; Ni et al. 2007). The primary objective of the study presented here is

Li et al. (2011). " $\mathrm{H}_{2} \mathrm{O}_{2}$ bleaching of pulp with adsorbed xylan," BioResources 6(1), 721-736. 722 
to bleach hardwood kraft pulp adsorbed with birch xylan by hydrogen peroxide and study the influence of bleaching operating variables (bleaching temperature, time, initial $\mathrm{pH}$, and $\mathrm{MgSO}_{4}$ dosage) upon paper properties. The whiteness, brightness, opacity, bulk, tensile strength and tear strength were examined to characterize the optical properties and physical properties of handsheets.

\section{EXPERIMENTAL}

\section{Materials}

A thoroughly washed (400-mesh), never-dried, non-beaten, industrially produced, bleached eucalyptus kraft pulp was used in our research. The bleaching sequence of DEOP-D-PO-D was used to produce this bleached pulp. Poly-DADMAC (Poly diallyl dimethyl ammonium chloride), with the molecular weight of 400,000 to 500,000, was purchased from Sigma-Aldrich Company. Commercial birchwood xylan which was also produced by Sigma-Aldrich Company was used. All reagents for the bleaching process were obtained from Samchun Pure Chemical Company.

\section{Adsorption of Xylan on Pulp Fibers}

To promote the interaction between xylan and fibers, $0.30 \%$ Poly-DADMAC based on oven dried pulp was added initially into the pulp slurry, and this treatment reversed the zeta potential of cellulosic fibers to positive. The stock was then stirred for 20 min and washed twice with 400-mesh to remove the unabsorbed Poly-DADMAC. Xylan was dissolved at $90{ }^{\circ} \mathrm{C}$ for $15 \mathrm{~min}$. After cooling down the solution to room temperature, $6.0 \%$ xylan based on oven dried pulp was added into the pulp and mixed for $20 \mathrm{~min}$.

\section{Chelation Pretreatment (Q Stage)}

In order to remove transition metal ions, the chelation pretreatment ( $Q$ stage) was performed at $70{ }^{\circ} \mathrm{C}, 5 \%$ pulp consistency for $30 \mathrm{~min}$, followed by washing. For this stage, $0.30 \%$ DTPA based on oven dried pulp was added and mixed well with pre-warmed pulp. The pulp was placed in a heat-proof polystyrene bag, sealed, and fully immersed in a preheated constant temperature water bath. For the duration of the experiment, the pulp was mixed every $15 \mathrm{~min}$.

\section{Hydrogen Peroxide Bleaching Process (P Stage)}

The hydrogen peroxide bleaching process ( $\mathrm{P}$ stage) was conducted at $10 \%$ pulp consistency with $2.0 \% \mathrm{H}_{2} \mathrm{O}_{2}$ based on oven dried pulp in plastic bags placed in a water bath. 3.0\% $\mathrm{Na}_{2} \mathrm{SiO}_{3}$ based on oven dried pulp was used as hydrogen peroxide stabilizer. Before adding bleaching chemicals, the pulp was pre-warmed. During the bleaching experiment, the pulp was mixed every $15 \mathrm{~min}$. The bleaching time, temperature, initial $\mathrm{pH}$, and $\mathrm{MgSO}_{4}$ dosage varied in the ranges $30 \mathrm{~min}$ to $60 \mathrm{~min}, 40$ to $80{ }^{\circ} \mathrm{C}, 10$ to 12 , and 0 to $0.30 \%$ according to different experiment designs. The required dosage of sodium hydroxide for $\mathrm{pH}$ of 10,11 , and 12 were $0.10 \%, 0.75 \%$ and $2.15 \%$ respectively. After bleaching, the pulp was washed to neutral $\mathrm{pH}$. 


\section{Handsheets Forming and Measurement of Properties}

Handsheets with basis weight of $80 \mathrm{~g} / \mathrm{m}^{2}$ were made from the bleached pulp and then were conditioned. The optical properties including brightness, whiteness, opacity, and physical properties including bulk, tensile strength, and tear strength were measured according to TAPPI standard methods.

\section{RESULTS AND DISCUSSION}

\section{Effect of Adsorption of Birch Xylan}

Table 1 compares the characteristics of hardwood kraft pulp before and after the adsorption of birch xylan. The results demonstrate that the adsorption of xylan improved the strength properties of pulp by $29.5 \%$ for tensile index and $22.7 \%$ for tear index, but the whiteness and brightness were decreased by $24.0 \%$ and $10.0 \%$ respectively. Besides, both the opacity and bulk were enhanced. It is commonly accepted that xylan attached on the fiber surface adds flexibility to the cell wall/fiber surface, resulting in stronger fiberto-fiber joints or greater contact area between the fibers (Bhaduri et al. 1995; Danielsson and Lindstrom 2005). Accordingly, the strength properties of pulp were promoted. Nevertheless, the residual lignin components in xylan can lead to a distinct reduction in the brightness of pulp, which affects the quality of paper to a great extent (Lee et al. 2010).

Table 1. Properties of Original Pulp and Xylan Treated Pulp

\begin{tabular}{|c|c|c|c|c|c|c|}
\hline Pulp & $\begin{array}{c}\text { Whiteness } \\
(\%)\end{array}$ & $\begin{array}{c}\text { Brightness } \\
(\%)\end{array}$ & $\begin{array}{c}\text { Opacity } \\
(\%)\end{array}$ & $\begin{array}{c}\text { Bulk } \\
\left(\mathrm{cm}^{3} / \mathrm{g}\right)\end{array}$ & $\begin{array}{c}\text { Tensile index } \\
(\mathrm{Nm} / \mathrm{g})\end{array}$ & $\begin{array}{c}\text { Tear index } \\
\left(\mathrm{mN} \cdot \mathrm{m}^{2} / \mathrm{g}\right)\end{array}$ \\
\hline Original & 77.8 & 87.0 & 80.9 & 2.87 & 4.75 & 1.32 \\
\hline Xylan treated & 59.1 & 78.2 & 84.7 & 2.94 & 6.15 & 1.62 \\
\hline
\end{tabular}

\section{Effect of Bleaching Time and Temperature}

The hydrogen peroxide bleaching process for researching the effect of bleaching time and temperature was conducted with $0.05 \% \mathrm{MgSO}_{4}$ dosage and from an initial $\mathrm{pH}$ of 11 .

Figure 1 indicates that brightness was enhanced with increasing of bleaching time and temperature, as the effect of delignification was enforced. Besides, in the first 30 min, the tendency was much more evident than later.

Figure 2 shows that when the bleaching temperature was $40{ }^{\circ} \mathrm{C}$, the opacity kept decreasing with continued bleaching. On the other hand, when the bleaching temperature was $60^{\circ} \mathrm{C}$ or $80^{\circ} \mathrm{C}$, the opacity decreased first and then increased again. It is supposed that some wood components including lignin were dissolved out during the bleaching and resulted in the collapse of fiber lumens. At the same time, alkaline swelling made the fibers more flexible and softer. As a result, the contact area between fibers was increased and the light scattering coefficient of paper sheet was reduced, which caused the decrease of opacity. Besides, bleaching of pulp diminished the light adsorption coefficient by removing light absorbing colored groups, which also reduced the opacity of paper, according to the Kubelka-Munk theory (Levlin and Söderhjelm 1999). When the bleaching temperature was high, it is assumed that xylan, which had been dissolved out 
and subjected to loss of acetyl groups, began to redeposit on fiber surface during the process of bleaching. In support of this mechanism, earlier research proved that the removal of acetyl groups happened in the earlier stage of bleaching could facilitate the readsorption of xylan and other hemicelluloses on fibers, as the solubility of the hemicelluloses without acetyl groups was much lower than the ones with acetyl groups (Reis et al. 1994; Gröndahl and Gatenholm 2005; Ni et al. 2007).

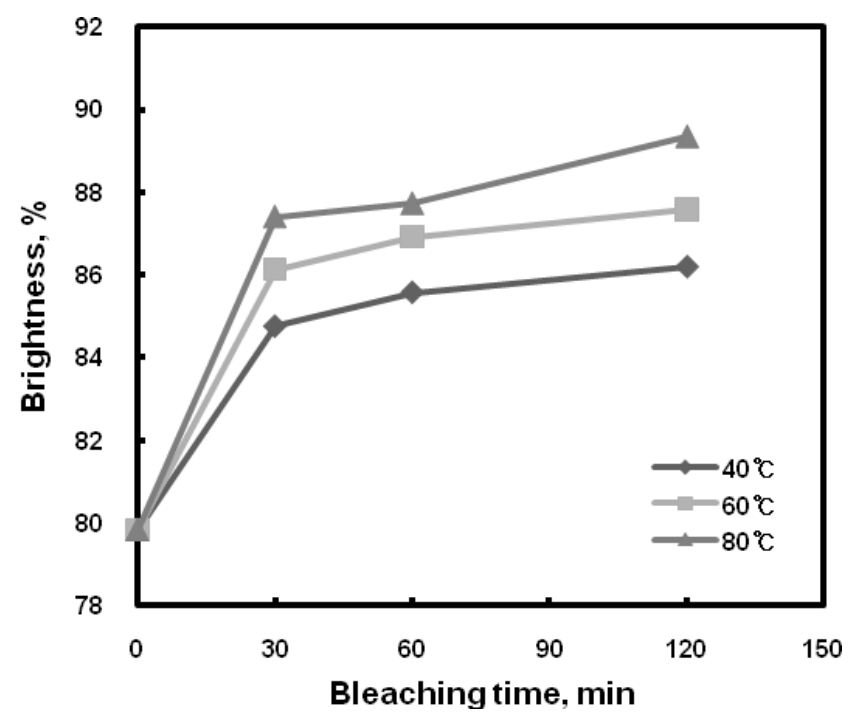

Fig. 1. Effect of bleaching time and temperature on brightness

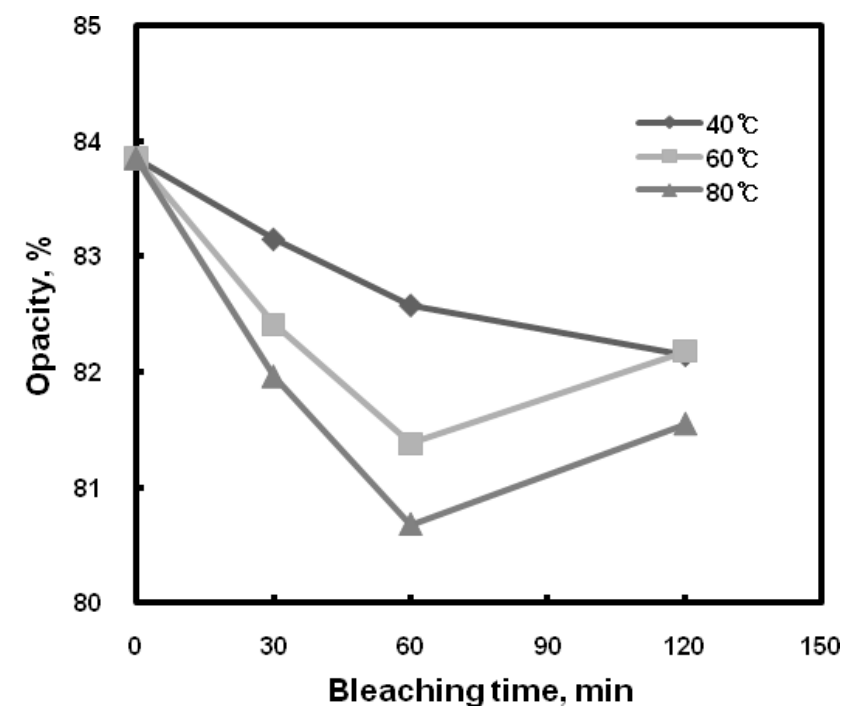

Fig. 2. Effect of bleaching time and temperature on opacity

Li et al. (2011). " $\mathrm{H}_{2} \mathrm{O}_{2}$ bleaching of pulp with adsorbed xylan," BioResources 6(1), 721-736. 725 
In Fig. 3, it can be observed that higher bleaching temperature resulted in poorer strength properties (i.e. tensile index and tear index). Besides, the tensile index and tear index were promoted steadily when the bleaching temperature was $40{ }^{\circ} \mathrm{C}$. However, in case of $60{ }^{\circ} \mathrm{C}$ and $80{ }^{\circ} \mathrm{C}$, the tensile index and tearing index dropped first, then went up again after bleaching for $60 \mathrm{~min}$. To understand this phenomenon, it is necessary to analyze the chemical and physical changes of pulp in the bleaching process.
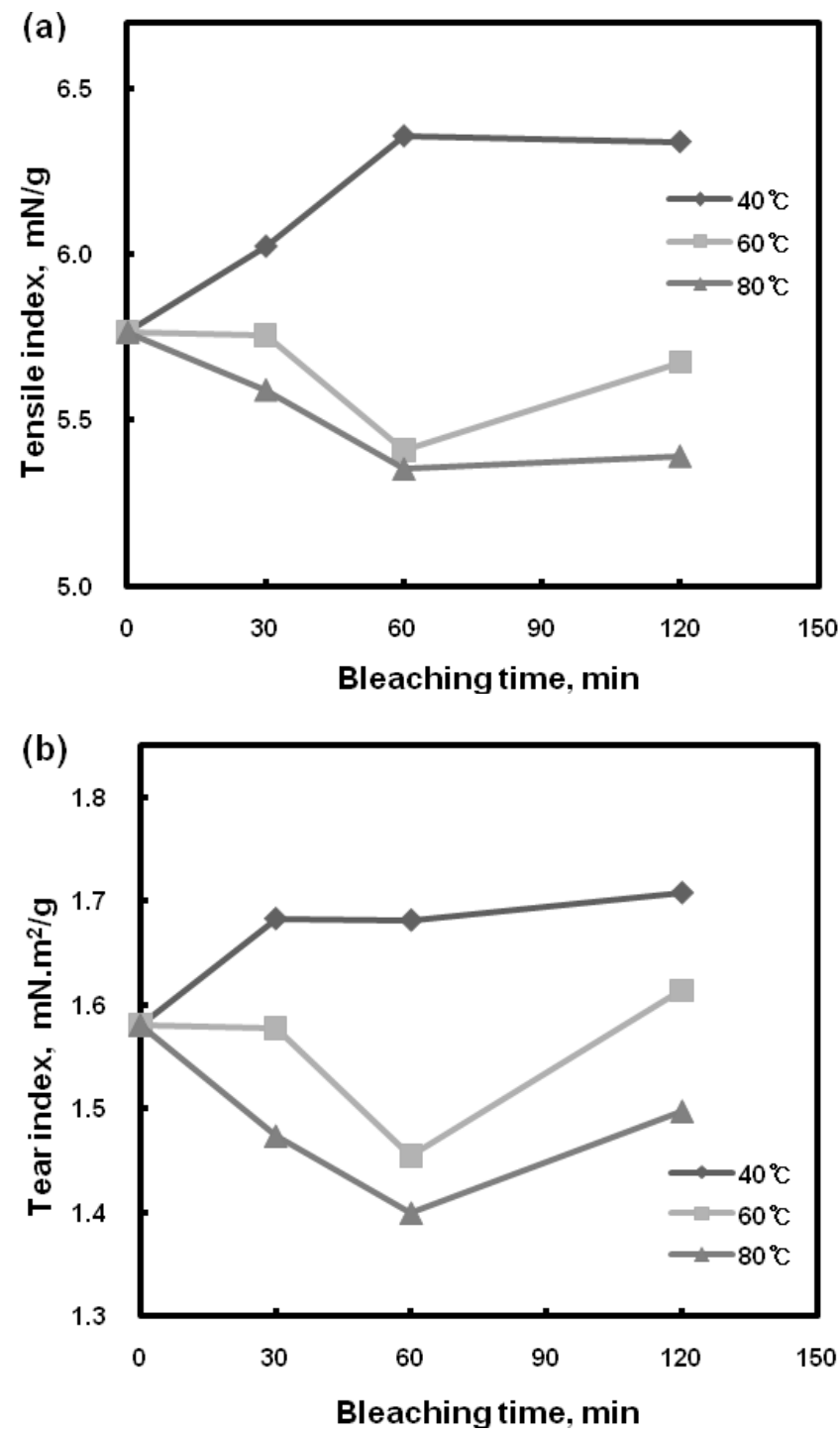

Fig. 3. Effect of bleaching time and temperature on tensile index (a) and tear index (b)

In general, there are five main factors affecting the properties of pulp. First of all, the dissolving of both adsorbed xylan from fiber surface and the original xylan located in the cell wall of fiber has negative effect on the physical properties of pulp (Simonson 1963; Fiserova et al. 1987). Besides, the bleached reaction species of alkaline hydrogen peroxide are hydroperoxy anions $\mathrm{HOO}^{-}$. The decomposition intermediates, such as

Li et al. (2011). " $\mathrm{H}_{2} \mathrm{O}_{2}$ bleaching of pulp with adsorbed xylan," BioResources 6(1), 721-736. 726 
hydroxyl $\mathrm{HO} \bullet$ and superoxide anion $\mathrm{O}_{2}{ }^{-} \bullet$ radicals, have generally undesirable influence in bleaching processes and also attack the carbohydrates, resulting in strength loss of the fibers (Zeronian and Inglesby 1995; Potůček and Milichovský 2000). Third, the collapse of fiber lumens caused by delignification and dissolving of other wood components increases the contacting area between fibers. Therefore, the fiber-to-fiber bonding is strengthened, which facilitates the development of mechanical properties of paper sheet (Pan et al. 2004). Fourth, the alkaline environment of bleaching increases the swelling of the cellulose fibers and thereby increases the surface area. That is believed to result in improved paper strength. Lastly, the removal of acetyl groups from hemicelluloses species promotes the re-disposition of xylan and other hemicelluloses, which also can be expected to affect the strength properties of sheet (Thornton et al. 1994; Dahlman et al. 2003).

When the bleaching temperature was $40{ }^{\circ} \mathrm{C}$, the effect of collapse of fiber lumens and swelling of cellulose fibers played a main role, while the effect of dissolving of xylan, deterioration of carbohydrates caused by hydrogen peroxide free radicals as well as re-disposition of xylan were weak due to the mild reaction condition, which led to the steady increasing of paper strength. On the other hand, when the bleaching temperature was raised to $60{ }^{\circ} \mathrm{C}$ or $80{ }^{\circ} \mathrm{C}$, the influence of dissolving of xylan and degradation of carbohydrates caused by hydrogen peroxide free radicals played a primary role in the earlier stage, while the impact of collapse of fiber lumens, swelling of cellulose fibers and re-disposition of xylan overcame the effect of former ones in the later stage.

\section{Effect of Initial pH}

The hydrogen peroxide bleaching process for researching the effect of initial $\mathrm{pH}$ was performed at $80{ }^{\circ} \mathrm{C}$, with $0.05 \% \mathrm{MgSO}_{4}$ dosage for $120 \mathrm{~min}$.

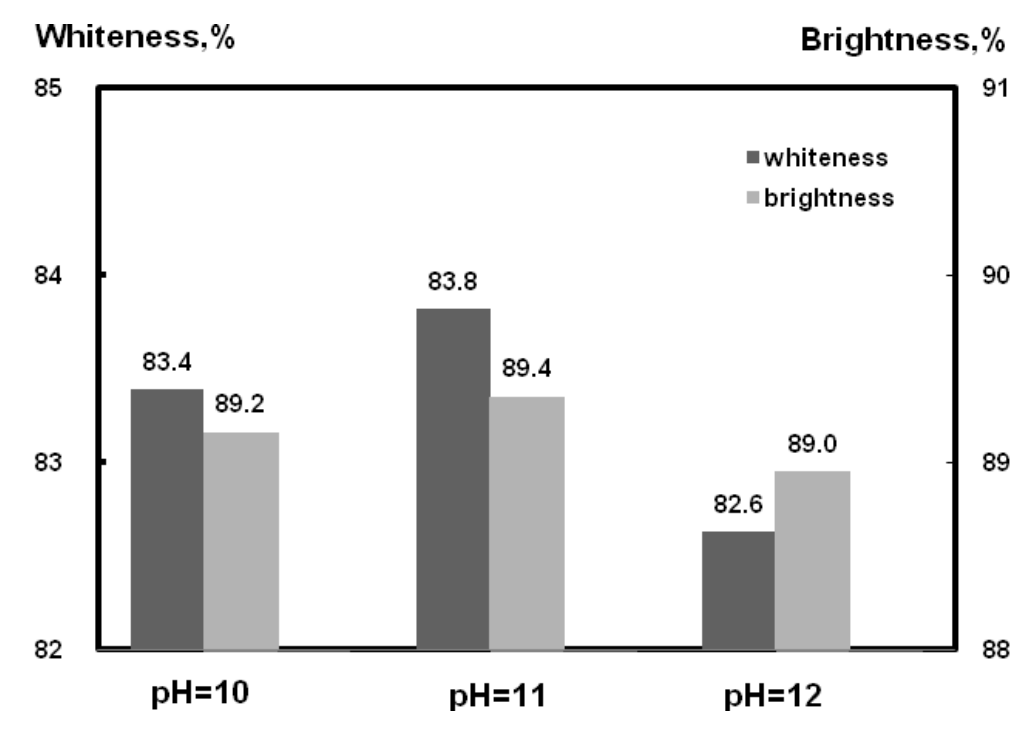

Fig. 4. Effect of initial pH on whiteness and brightness 
The data in Fig. 4 demonstrates that the hydrogen peroxide bleaching from initial $\mathrm{pH} 11$ provided both the highest whiteness and the highest brightness value. The explanation is that lower initial pHs represented weak alkaline conditions that could not supply enough $\mathrm{OOH}^{-}$for the bleaching system. As a result, insufficient bleaching caused lower whiteness and brightness. However, when the initial $\mathrm{pH}$ was too high, excess alkali increased hydroxyl ions, which in turn produced perhydroxyl ion too rapidly to be used. That could lead to the following reaction (Johnson et al. 2002).

$$
\mathrm{H}_{2} \mathrm{O}_{2}+\mathrm{OOH}^{-} \longleftrightarrow \mathrm{OH}^{-}+\mathrm{O}_{2}(\mathrm{~g})+\mathrm{H}_{2} \mathrm{O}
$$

Consequently, hydrogen peroxide would be decomposed before it was used for bleaching. At the same time, pulp could also become darkened due to alkaline darkening reactions, which can be simply described as (Johnson et al. 2002),

$$
\text { lignin }+\mathrm{OH}^{-} \longrightarrow \text { chromophoric groups }
$$

where phenolic lignin units could be oxidized by alkali to light absorbing structures, resulting in lower optical properties.

The experimental results for the effect of initial $\mathrm{pH}$ on bulk, opacity, tensile index and tear index are shown in Figs. 5 and 6, respectively. It is obvious that both bulk and opacity declined with the increasing of initial $\mathrm{pH}$, whereas tensile index and tear index increased greatly. The reason is that higher initial $\mathrm{pH}$ created a stronger alkaline environment, which facilitated the collapse of fiber lumens caused by delignification and dissolving of other wood components. As a result, bulk was decreased. But the collapse of fiber lumens increased the contacting area between fibers. In addition to the better swelling of fibers, the strength properties of paper were promoted evidently. At the same time, owing to the reduction of non-contacting areas between fibers, the light scattering coefficient went down and thereby the opacity declined.

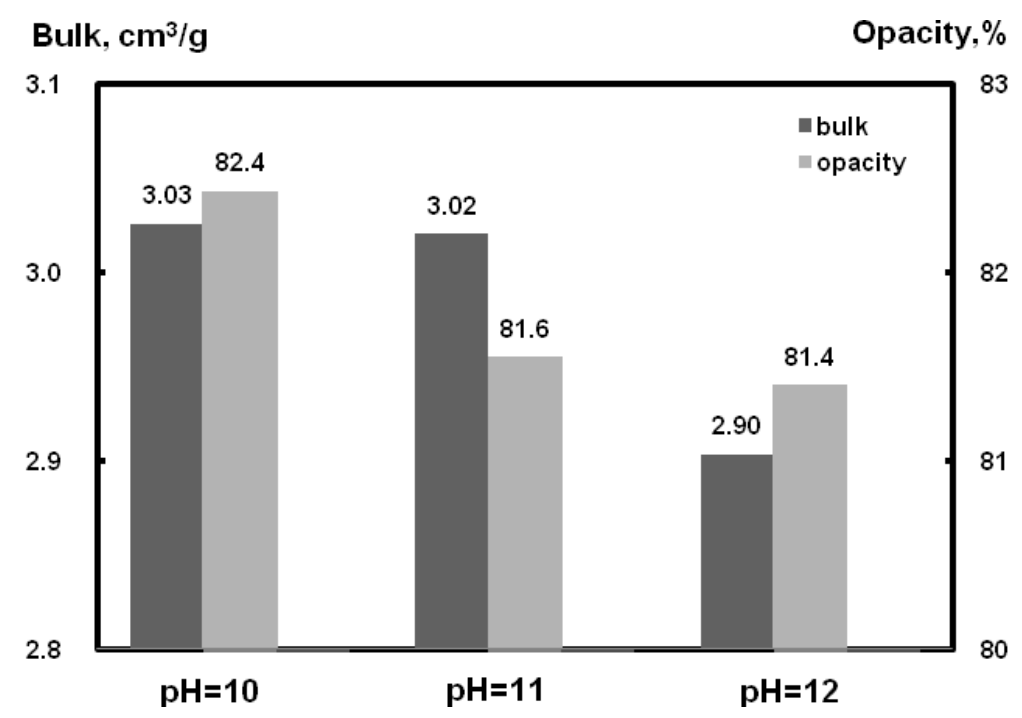

Fig. 5. Effect of initial pH on bulk and opacity 


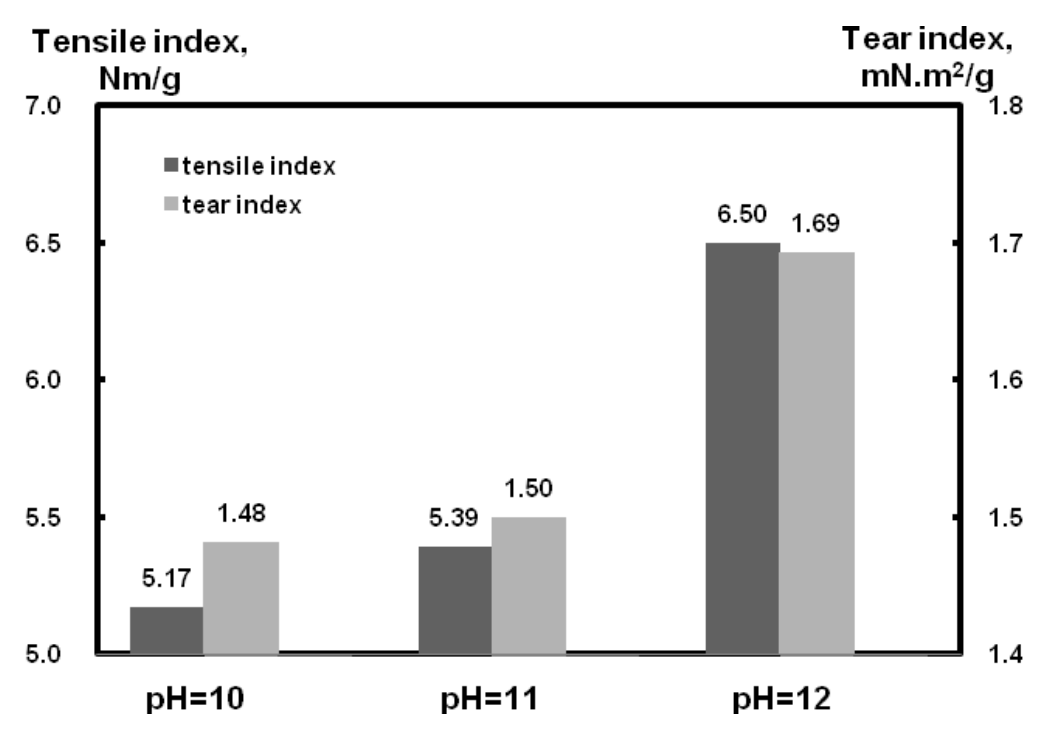

Fig. 6. Effect of initial $\mathrm{pH}$ on tensile index and tear index

\section{Effect of $\mathrm{MgSO}_{4}$ Dosage}

The hydrogen peroxide bleaching process for researching the effect of $\mathrm{MgSO}_{4}$ dosage was conducted at $80^{\circ} \mathrm{C}$, from an initial $\mathrm{pH}$ of 11 and for $120 \mathrm{~min}$.

According to Figs. 7 through 9, it appears that both optical properties and mechanical properties were improved with the increasing addition of $\mathrm{MgSO}_{4}$.

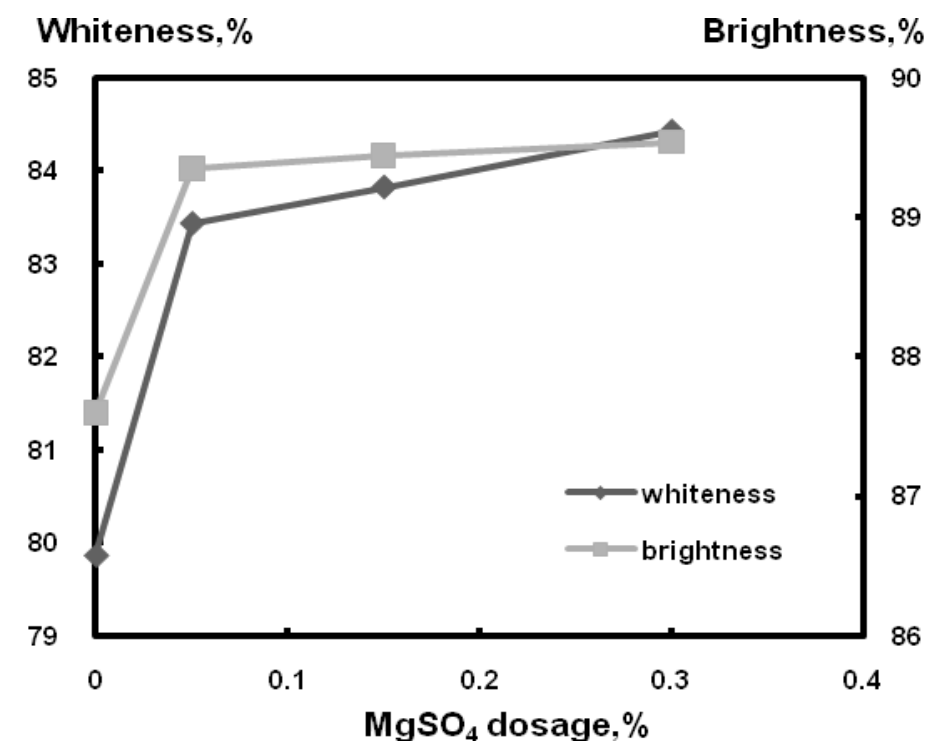

Fig. 7. Effect of $\mathrm{MgSO}_{4}$ dosage on whiteness and brightness

Li et al. (2011). " $\mathrm{H}_{2} \mathrm{O}_{2}$ bleaching of pulp with adsorbed xylan," BioResources 6(1), 721-736. 729 


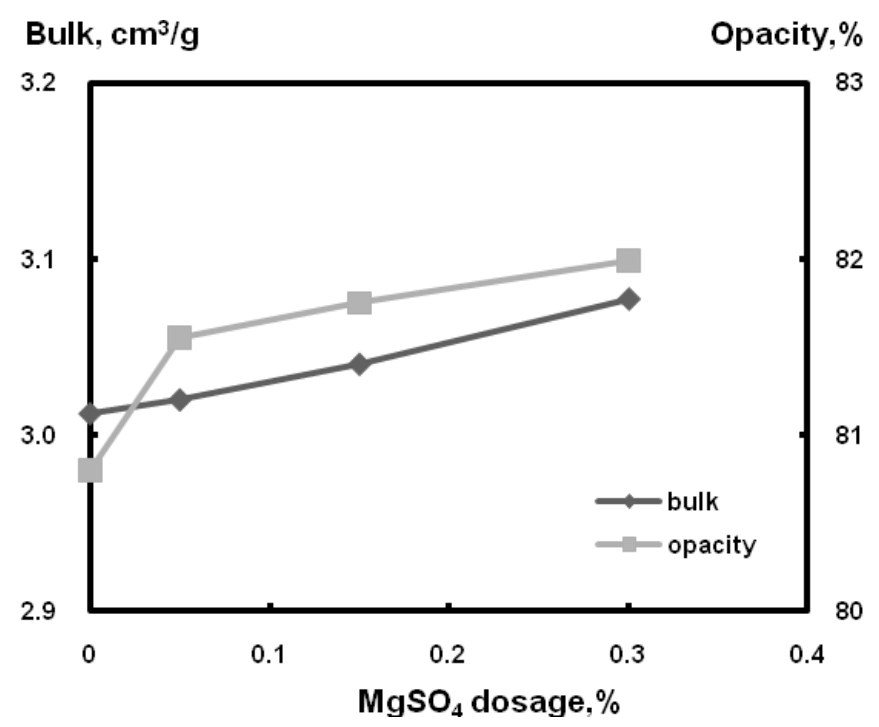

Fig. 8. Effect of $\mathrm{MgSO}_{4}$ dosage on bulk and opacity

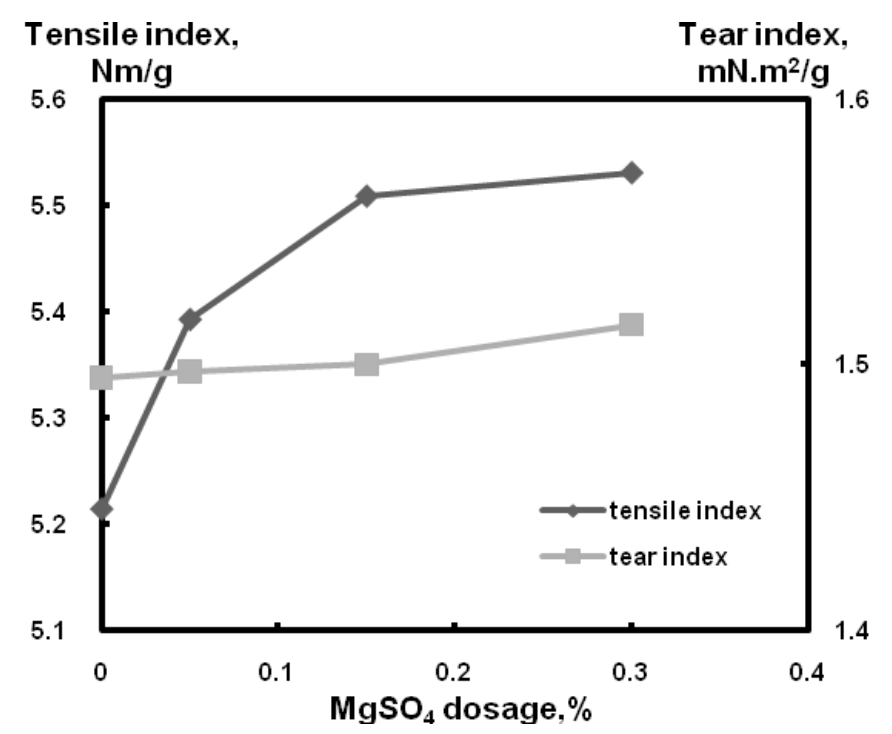

Fig. 9. Effect of $\mathrm{MgSO}_{4}$ dosage on tensile index and tear index

Previous studies proved that peroxide can be catalytically decomposed by some transition metal ions such as iron, manganese, and copper as follows (Persley and Hill 1996):

$$
\begin{aligned}
& \mathrm{H}_{2} \mathrm{O}_{2}+\mathrm{M}^{2+} \longleftrightarrow \mathrm{M}^{3+}+\mathrm{OH}^{-}+\mathrm{OH} \bullet \\
& \mathrm{H}_{2} \mathrm{O}_{2}+\mathrm{M}^{3+} \longleftrightarrow \mathrm{M}^{2+}+\mathrm{H} \bullet+\mathrm{OOH} \bullet
\end{aligned}
$$




$$
\begin{aligned}
& \mathrm{OOH} \bullet \longleftrightarrow \mathrm{O}_{2}(\mathrm{~g})+\mathrm{H} \bullet \\
& \mathrm{H} \bullet+\mathrm{OH} \bullet \longleftrightarrow \mathrm{H}_{2} \mathrm{O}
\end{aligned}
$$

Therefore, a part of hydrogen peroxide was consumed without taking part in the bleaching reaction. In addition, the newly created free radicals attacked the carbohydrates, leading to a loss of fiber strength. However, magnesium sulfate, as an alkaline earth metal, can inhibit this catalytic decomposition, stabilize peroxide, and protect the carbohydrates (Zeronian and Inglesby 1995). Moreover, earlier studies concerning the adsorption of carboxymethyl cellulose (CMC) on the pulp has shown that a higher electrical conductivity of the pulp slurry causes increased an amount of CMC to be adsorbed onto the pulp (Watanabe et al. 2004; Liimatainen et al. 2009). Similarly, the addition of $\mathrm{MgSO}_{4}$ could increase the electrical conductivity of the pulp, which was also expected to favor greater retention of the xylan on the fibers. As a result, both better optical properties and physical properties of paper could be obtained with the usage of $\mathrm{MgSO}_{4}$.

\section{Comparison of Pulp Properties in Different Phases}

Figures 10 and 11 compare the properties of the original pulp, xylan treated pulp, chelating agent-treated pulp, and pulp bleached at different temperatures, with $0.05 \%$ $\mathrm{MgSO}_{4}$ dosage, from an initial $\mathrm{pH}$ of 11 , for $120 \mathrm{~min}$. The results show that the adsorption of xylan improved the strength properties of pulp, but the whiteness and brightness were decreased. The chelation pretreatment with DTPA provided a slight increase in optical properties and a reduction in strength properties.

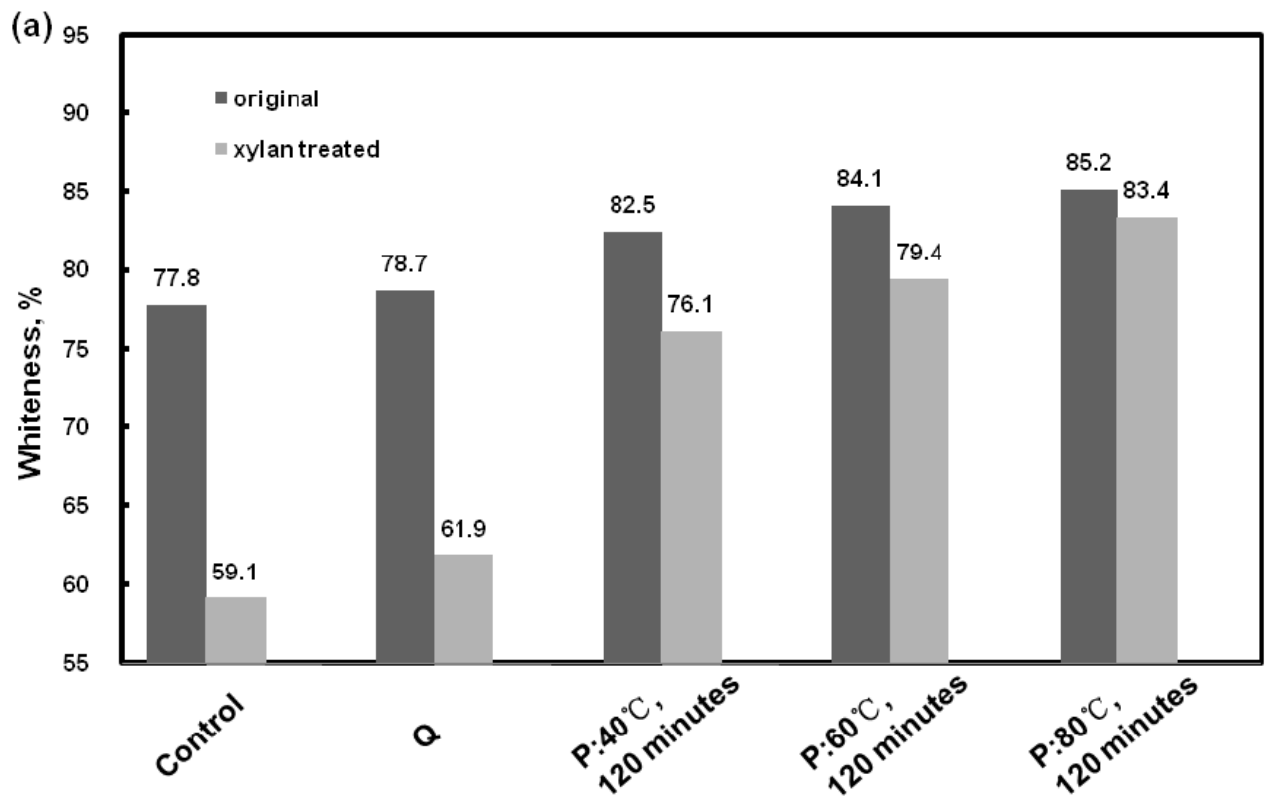

Fig. 10a. Comparison of whiteness (a) and brightness (b) 


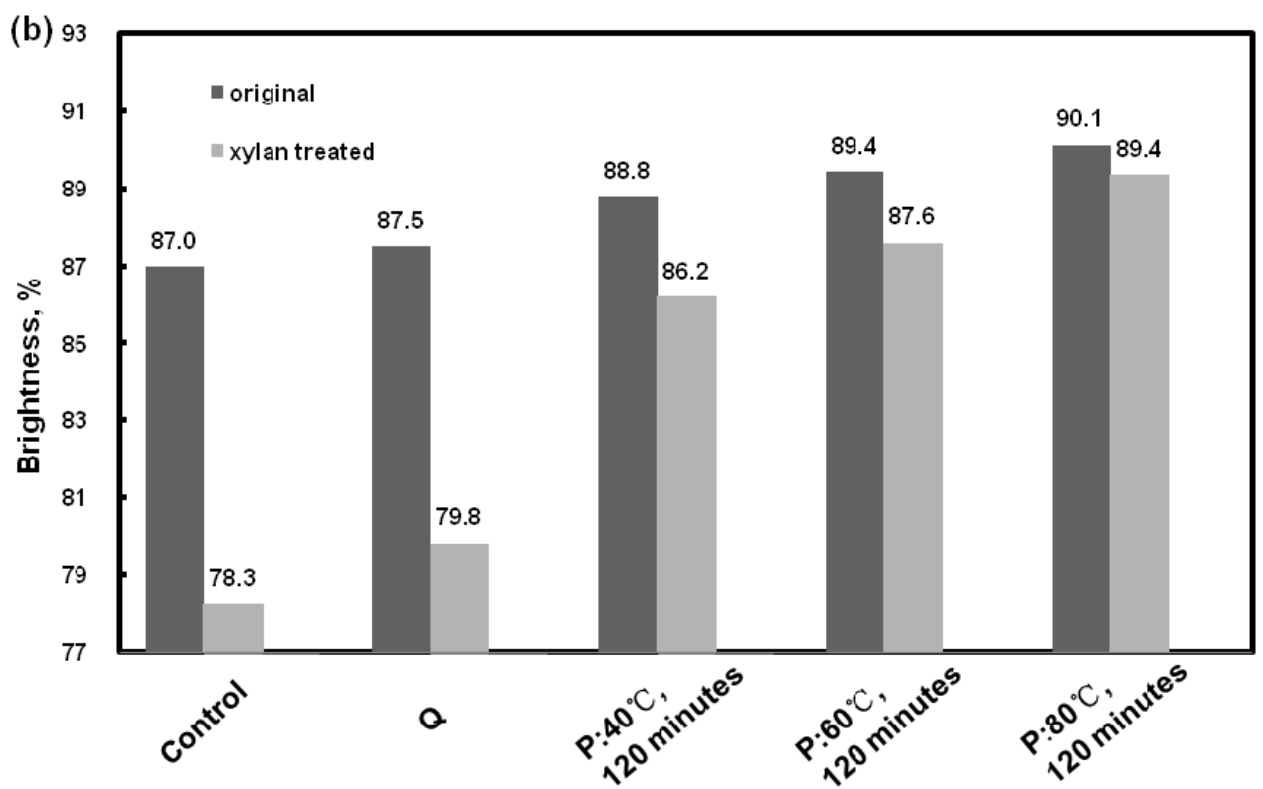

Fig. 10b. Comparison of whiteness (a) and brightness (b)

The hydrogen peroxide bleaching reduced the impact of adsorbed xylan on whiteness and brightness, while the effect on improving strength properties was still remained. Most importantly, when the bleaching process parameters were set properly, both optical qualities and physical properties were enhanced compared to the original pulp.

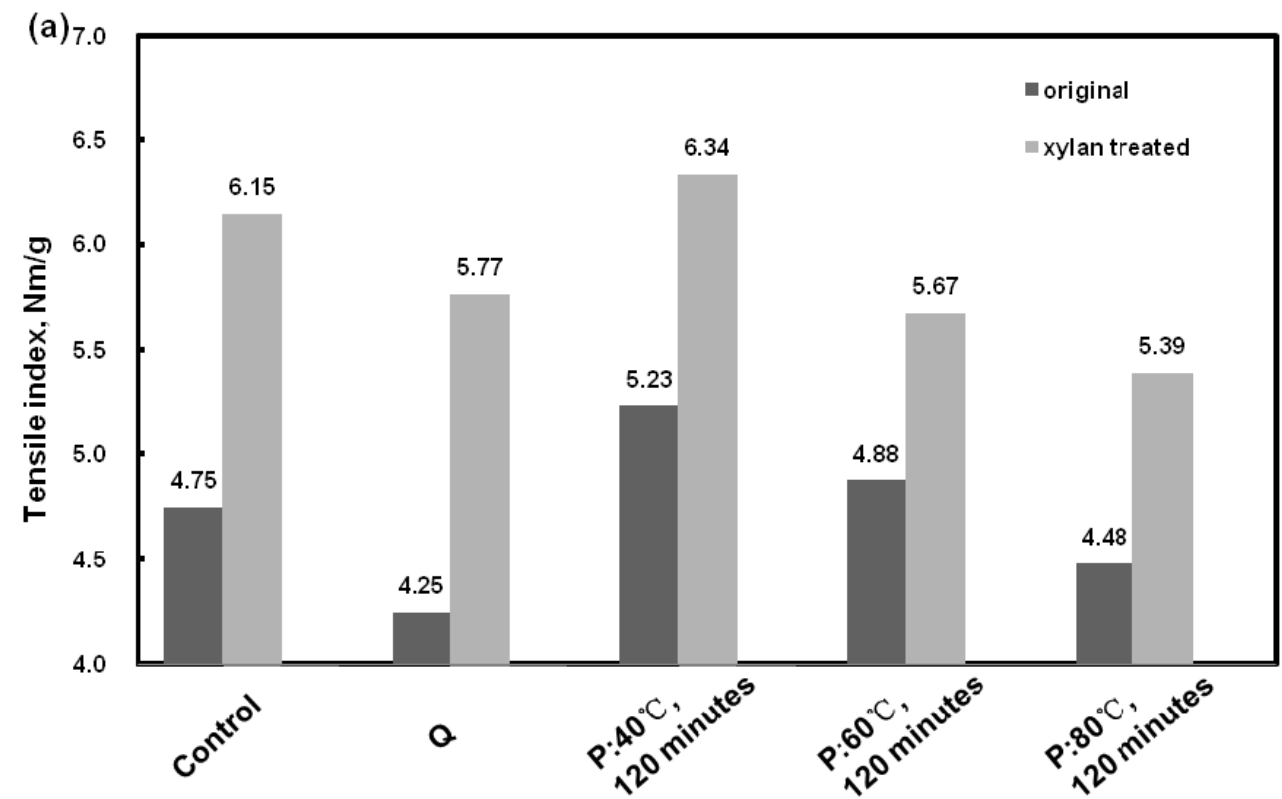

Fig. 11a. Comparison of tensile index (a) and tear index (b) 


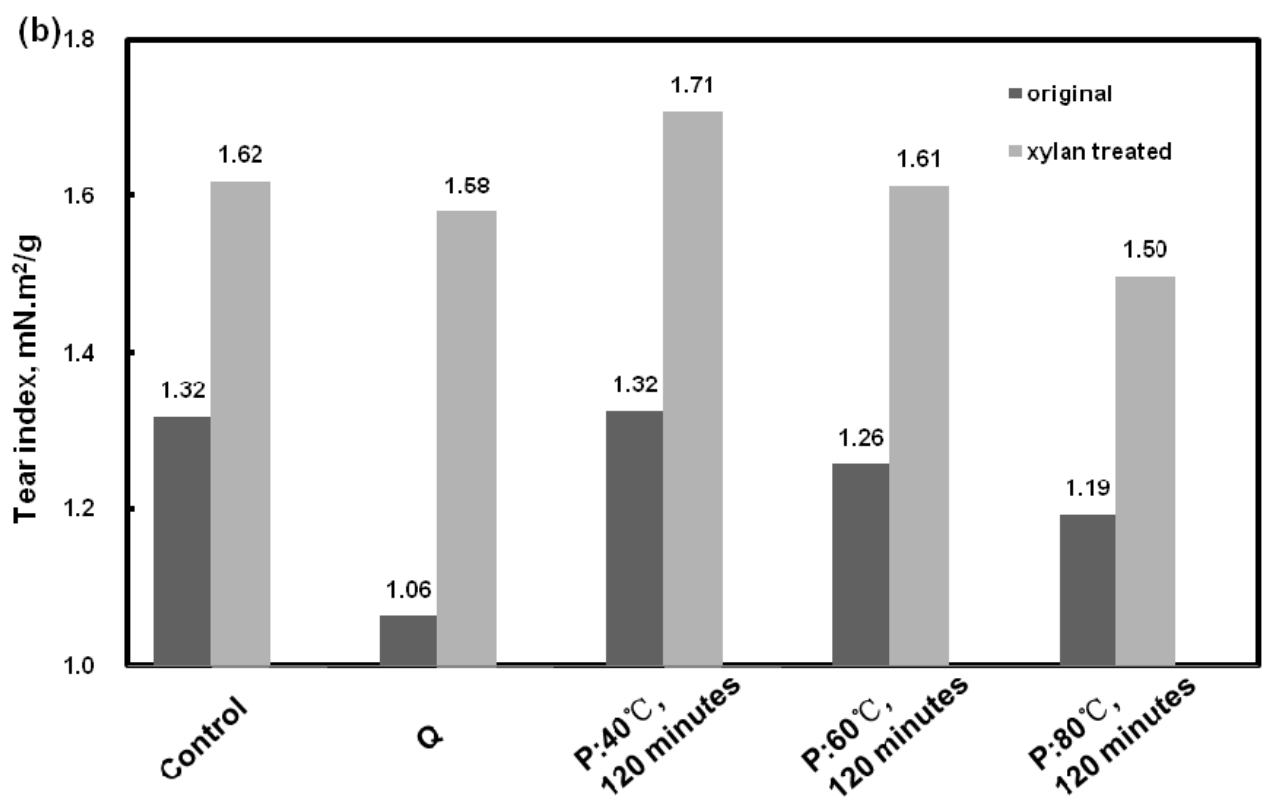

Fig. 11b. Comparison of tensile index (a) and tear index (b)

For example, when bleaching temperature was $60{ }^{\circ} \mathrm{C}$ and bleaching time was 120 min, the whiteness and brightness of bleached pulp were as high as $79.4 \%$ and $87.6 \%$. Moreover, the tensile index and tear index were promoted by $19.4 \%$ and $22.0 \%$ respectively. Consequently, it is proved that hydrogen peroxide bleaching is a suitable bleaching process for the hardwood kraft pulp with adsorbed birch xylan.

\section{CONCLUSIONS}

1. The adsorption of birch xylan on hardwood kraft pulp fibers improves the strength properties of paper, but reduces the whiteness and brightness.

2. At low bleaching temperature, for example $40{ }^{\circ} \mathrm{C}$, the brightness is enhanced, the opacity keeps decreasing, while the mechanical properties (i.e. tensile index and tearing index) is promoted steadily with the extension of bleaching time. On the other hand, when the bleaching temperature is high, for example $60{ }^{\circ} \mathrm{C}$ and $80{ }^{\circ} \mathrm{C}$, the brightness is increased; the opacity and physical properties are first decreased and then improved again with additional bleaching time.

3. Higher temperature of bleaching provides better whiteness and brightness, but lower opacity, tensile index, and tear index.

4. The highest whiteness and brightness value can be obtained by bleaching from initial $\mathrm{pH}$ 11. In addition, with the increase of initial $\mathrm{pH}$, the bulk and opacity declines, whereas the tensile index and tear index are raised significantly.

5. The whiteness, brightness, opacity, bulk, and strength properties are promoted by addition of $\mathrm{MgSO}_{4}$ dosage. 
6. Hydrogen peroxide bleaching is an applicable method for bleaching hardwood kraft pulp with adsorption of birch xylan. With that, both good mechanical properties and optical properties of pulp can be achieved.

\section{ACKNOWLEGEMENT}

This work was supported by the Korea Forest Service.

\section{REFERENCES CITED}

Abrantes, S., Amaral, E., Costa, A. P., Shatalov, A. A., and Duarte, A. P. (2007). "Hydrogen peroxide bleaching of Arundo donax L. kraft-anthraquinone pulp - Effect of a chelating stage," Industrial Crops and Products 25(3), 288-293.

Bhaduri, S. K., Ghosh, I. N., and Sarkar, N. L. D. (1995). "Ramie hemicelluloses as beater additive in papermaking from jute-stick kraft pulp," Industrial Crops and Products 4(2), 79-84.

Björkman, A. (1957). "Finely divided wood. III. Extraction of lignincarbohydrate complexes with neutral solvents," Svensk Papperstidning 60, 243-251.

Dahlman, O., Sjöberg, J., Jansson, U.B., and Larsson, P.O. (2003). "Effects of surface hardwood xylan on the quality of softwood pulps," Nordic Pulp and Paper Research Journal 18(3), 310-315.

Danielsson, S., and Lindstrom, M. E. (2005). "Influence of birch xylan adsorption during kraft cooking on softwood pulp strength," Nordic Pulp and Paper Research Journal 20(4), 436-441.

Fiserova, N., Opalena, E., and Farkas, J. (1987). "Effect of hemicelluloses on the papermaking properties of pulps prepared from poplar wood," Cellulose Chemistry and Technology 21(4), 419-430.

Eriksson, Ö., Goring, D. A. I., and Lindgren, B. O. (1980). "Structural studies on the chemical bonds between lignins and carbohydrates in spruce wood," Wood Science and Technology 14(4), 267-279.

Gröndahl, M., and Gatenholm, P. (2005). "Role of acetyl substitution in hardwood xylan," Polysaccharides: Structural Diversity and Functional Versatility, 2nd Edn., Dumitriu, S. (ed.), Marcel Dekker Inc., New York, 509-514.

Johnson, D. A., Park, S., Genco, J. M., Gibson, A., Wajer, M., and Branch, B. (2002). "Hydrogen peroxide bleaching of TMP pulps using $\mathrm{Mg}(\mathrm{OH})_{2}$," Proceedings of TAPPI Pulping and Engineering Conference, San Diego, Canada.

Joseleau, J. P., Comatat, J., and Ruel, K. (1992). Progress in Biotechnology, Elsevier Science Publiser, 7, 1-15.

Köhnke, T., Brelid, H., and Westman, G. (2009). “Adsorption of cationized barley husk xylan on kraft pulp fibres: Influence of degree of cationization on adsorption characteristics," Cellulose 16, 1109-1121. 
Köhnke, T., and Gatenholm, P. (2007). "Modification of cellulose fibres by controlled xylan adsorption and its effect on softwood pulp properties," 14th International Symposium on Wood, Fibre and Pulping Chemistry, Durban, South Africa. 25-28.

Lapierre, L., Bouchard, J., Berry, R. M., and Vanlierop, B. (1995). "Chelation prior to hydrogen-peroxide bleaching of kraft pulps - An Overview," Journal of Pulp and Paper Science 21(8), J268-J273.

Lawoko, M., Henriksson, G., and Gellerstedt, G. (2005). "Structural differences between the lignin-carbohydrate complexes present in wood and in chemical pulps," Biomacromolecules 6, 3467-3473.

Lee, S. H., Lee, H. L., Youn, H. J., and Zhu, H. X. (2010). "The investigation to apply birchwood xylan for improvement of dry strength of paper," PAPTAC Annual Meeting. Montreal, Canada.

Levlin, J. E., and Söderhjelm, L. (1999). "Pulp and paper testing," Papermaking Science and Technology, Fapet Oy, Helsinki, Finland, 175-176.

Liimatainen, H., Haavisto, S., Haapala, A., and Niinimäki, J. (2009). "Influence of adsorbed and dissolved carboxymethyl cellulose on fiber suspension dispersing, dewaterability, and fines rentention," Bioresources 4(1), 321-340.

Lindström, T., Wågberg, L., and Larsson, T. (2005). "On the nature of joint strength in paper - a review of dry and wet strength resins used in paper manufacturing," Proceedings of the 13th Fundamental Research Symposium, Cambridge, UK., 1, $457-$ 562.

Lundquist, K., Simonsson, R., and Tingsvik, K. (1979). "On the occurrence of carbohydrates in milled wood lignin," Svensk Papperstidn 82, 272-275.

Meshitsuka, G., Lee, Z., and Nakano, J. J. (1982). "Studies of the nature of lignincarbohydrate bonding," Wood Chemistry and Technology 2, 251-267.

Ni, Y., He, Z., and Zhou, Y. (2007). "Alkaline peroxide bleaching and properties of high yield pulp," Word Pulp and Paper 26(3), 10-18.

Pan, G. X. (2004). "Relationship between dissolution of fiber materials and development of pulp strength in alkaline peroxide bleaching of mechanical pulp," Holzforschung 58(4), 369-374.

Persley, J. R., and Hill, R. T. (1996). "Peroxide bleaching of (chemi) mechanical pulps," Pulp Bleaching, Principles and Practice, TAPPI Press, 459-489.

Potůček, F., and Milichovský, M. (2000). "Kraft pulp bleaching with hydrogen peroxide and peracetic acid," Chemical Papers 56(6a), 406-411.

Reis, D., Vian, B., and Roland, J.C. (1994). "Cellulose-glucuronoxylans and plant cell wall structure," Micron 25, 171-187.

Schimizu, K. (1991). “Chemistry of hemicelluloses," In: Wood and Cellulosic Chemistry Hon, D. N.-S., and Shiraishi, N. (eds.), Marcel Dekker Inc., New York, 177-214.

Schönberg, C., Oksanen, A., Suurnäkki, A., Kettunen, H., and Buchert, J. (2001). "The importance of xylan for the strength properties of spruce kraft pulp fibres," Holzforschung 55, 639-644.

Shatalov, A. A., and Pereira, H. (2005). "Arundo donax L. reed: New perspective for pulping and bleaching. Part4. Peroxide bleaching of organosolv pulps," Bioresource Technology 96, 865-872. 
Simonson, R. (1963). "The hemicellulose in the sulphate pulping process. I. Isolation of hemicellulose fractions from sulphate cooking liquors," Svensk Papperstidning 66(20), 839.

Thornton, J., Ekman, R., and Holmbom, B. (1994). "Polysaccharides dissolved from Norway spruce intherno-mechanical pulping and peroxide bleaching," Journal of Wood Chemistry and Technology 14(2), 159-175.

Walsh, P. B. (1991). "Hydrogen peroxide: Innovations in chemical pulp bleaching," Tappi Journal 74(1), 81-83.

Watanabe, M., Gondo, T., and Kitao, O. (2004). "Advanced wet-end system with carboxymethyl-cellulose," Tappi Journal 3(5), 15-19.

Westbye, P., Köhnke, T., and Gatenholm, P. (2008). "Fractionation and characterization of xylan rich extracts from birch," Holzforschung 62(1), 31-37.

Westbye, P., Svanberg, C., and Gatenholm, P. (2006). "The effect of molecular composition of xylan extracted from birch on its assembly onto bleached softwood kraft pulp," Holzforschung 60(2), 143-148.

Zeronian, S. H., and Inglesby, M. K. (1995). "Bleaching of cellulose by hydrogen peroxide," Cellulose 2, 265-272.

Article submitted: Sep. 26, 2010; Peer review completed: November 19, 2010; Revised version received: December 30, 2010; Accepted: January 15, 2011; Published: January $16,2011$. 